\title{
Evaluation of anti-diabetic effect of Trigonella foenum graecum Linn. Leaf extract in streptozotocin induced diabetic rats
}

\author{
Ramya Premanath • N. Lakshmidevi • K. Jayashree • \\ R. N. Suresh
}

Received: 10 February 2011 / Accepted: 5 July 2012 / Published online: 12 August 2012

(C) Research Society for Study of Diabetes in India 2012

\begin{abstract}
Trigonella foenum graecum leaves are widely used as a vegetable throughout India and have a long history of medicinal use in Ayurveda and Chinese medicine. Even though the leaves of this plant are used in diabetes mellitus, there have been no in vivo studies to prove its efficacy. The aim of this study was to know the efficacy of ethanol extract of T. foenum graecum leaves on blood glucose levels, antioxidant enzymes, islets cells of pancreas, creatinine and urea levels in normal and streptozotocin induced diabetic rats. Diabetes was induced by streptozotocin $(45 \mathrm{mg} / \mathrm{kg}$ b.w. in $0.9 \%$ cold saline). Two doses ( 250 and $500 \mathrm{mg} / \mathrm{kg}$ b.w.) of the extracts were administered in the study. The activity was compared with the reference standard glibenclamide $(0.5 \mathrm{mg} / \mathrm{kg}$ b.w. $)$ for various biochemical and histopathological parameters. The data was analysed by one way ANOVA followed by Turkey's post hoc test. The activity of the extract in reducing blood glucose, creatinine and urea levels, in enhancing antioxidant enzyme activity and restoring and
\end{abstract}

R. Premanath $(\bowtie) \cdot N$. Lakshmidevi

DOS in Microbiology, University of Mysore,

Mysore, India

e-mail:rmy300@yahoo.co.in

K. Jayashree

Department of Pathology, JSS Medical College,

Mysore, India

R. N. Suresh

Department of Pharmacology, JSS Medical College,

Mysore, India regenerating islet cells of pancreas was comparable to glibenclamide. The result suggests that ethanol leaf extract of $T$. foenum graecum possesses significant antidiabetic property.

Keywords Diabetic rats · Trigonella foenum graecum . Antihyperglycemic effect · Antioxidant enzyme activity

\section{Introduction}

Diabetes Mellitus (DM) is a leading metabolic disorder worldwide, caused by a deficiency in the production of insulin in the beta cells of pancreas, or by the insulin resistance. Such a deficiency results in the increased concentration of glucose in the blood which results in secondary complications affecting eyes, kidneys, nerves and arteries. Experimental evidences suggest the involvement of free radicals in the pathogenesis of diabetes [1] and more importantly in the development of diabetic complications [2].

Trigonella foenum graecum Linn. commonly known as Fenugreek belongs to the family Fabaceae, which is an annual, herbaceous and aromatic plant. It is one of the oldest medicinal plants, originating in India and Northern Africa. The leaves and seeds, which mature in long pods, are used to prepare extracts or powders for medicinal use. In India, fenugreek seeds are commonly consumed as a condiment. Fresh and dried fenugreek leaves and tender stems are edible which are widely used as a vegetable. Fenugreek 
is reported to have anti-diabetic, anti-fertility, anticancer, anti-microbial, anti-parasitic, lactation stimulant and hypocholesterolemic effects [8].

In view of the promising anti-diabetic potential of fenugreek seeds, we have investigated the efficacy and safety of ethanol extract of its leaves on blood glucose levels, its effect on kidney parameters, antioxidant enzyme activity in liver and islet cells of pancreas in streptozotocin induced diabetic rats.

\section{Material and Methods}

Plant material

Fresh and healthy leaves of $T$. foenum graecum were obtained from local market. The sample specimen was identified based on the taxonomical characteristics and deposited in the herbarium of department of Applied Botany. The leaves were washed thoroughly in distilled water and the surface water was removed by air drying under shade. The leaves were subsequently dried in a hot air oven at $40^{\circ} \mathrm{C}$ for $48 \mathrm{~h}$, powdered and used for extraction.

\section{Preparation of solvent extract}

Fifty grams of the powdered material was extracted initially with $300 \mathrm{ml}$ of ethanol for $24 \mathrm{~h}$ at $23 \pm 2{ }^{\circ} \mathrm{C}$. The extract was filtered with sterile Whatman filter paper into a clean conical flask. Second extraction was carried out with same amount of solvent for another $24 \mathrm{~h}$ at $23 \pm 2{ }^{\circ} \mathrm{C}$ and filtered. The extracts were later pooled and transferred into the sample holder of the rotary flash evaporator for the evaporation of the solvents. The evaporated extract so obtained was preserved at $4^{\circ} \mathrm{C}$ in airtight bottle until further use [9]. The suspension of the extract was prepared by dissolving the weighed amount in freshly prepared $1 \%$ gum arabic solution.

\section{Animals}

Adult healthy Albino rats of Wistar strain of either sex weighing 120-160 g with no prior drug treatment were used in the present study. Animals were maintained at $22 \pm 2{ }^{\circ} \mathrm{C}$ with $12 \mathrm{~h}$ light and dark cycle. The animals were fed on standard pellet diet and had free access to diet and water throughout the experiment. Animals that are described as fasting were deprived of food for at least $16 \mathrm{~h}$ but were allowed free access to drinking water. Animal study was performed in Central Animal Facility, JSS Medical College,
Mysore, with due permission from Institutional Animal Ethics Committee.

Experimental design

The animals were randomly divided into the seven groups with six animals in each group. Group A served as saline control, group $\mathrm{B}$ and $\mathrm{C}$ served as normal controls who were administered 250 and $500 \mathrm{mg} / \mathrm{kg}$ body weight (b.w.) of leaf extract respectively to know the toxic effects of the extracts if any on kidney and liver, group D as the diabetic control, group $\mathrm{E}$ as the standard drug (glibenclamide, $0.5 \mathrm{mg} / \mathrm{kg}$ b.w.) control and group $F$ and $G$ were diabetics treated with 250 and $500 \mathrm{mg} / \mathrm{kg}$ b.w. of leaf extract respectively. Saline, leaf extract and the standard drug were administered orally using a mouth gauge. During the study period, body weight, food and water intake of rats were monitored regularly.

After initial determination of $16 \mathrm{~h}$ fasting blood glucose levels (blood drawn through the tail vein puncture) animals were given single intraperitoneal injection of streptozotocin at a dose of $45 \mathrm{mg} / \mathrm{kg}$ b.w. freshly dissolved in cold $0.9 \%$ saline [10]. Fasting blood glucose levels were recorded after 5 days. Animals that developed stable hyperglycemia with fasting blood glucose levels more than $200 \mathrm{mg} / \mathrm{dl}$ were selected for the study.

Rats were fasted overnight; blood was drawn from the tail by tail vein puncture during the experimental period and from cardiac puncture at the end of the experimental period (after 28 days) under anaesthesia. Serum was separated by centrifuging the collected blood samples at $10,000 \mathrm{rpm}$ for $10 \mathrm{~min}$ at $4{ }^{\circ} \mathrm{C}$ and used for the estimation of creatinine and urea.

Urine from normal control rats, diabetic and treated diabetic rats were collected under a layer of toluene by keeping the rats in metabolic cages for $24 \mathrm{~h}$. Collected urine samples were filtered through filter paper, centrifuged and stored at $4{ }^{\circ} \mathrm{C}$ until further analysis.

Preparation of liver tissue homogenate

After 28 days, rats were dissected under anaesthesia. Liver was rinsed in ice cold distilled water followed by chilled $0.9 \%$ saline. About $1 \mathrm{~g}$ of liver tissue was homogenized in $10 \mathrm{ml}$ of $10 \mathrm{mM}$ phosphate buffered saline (pH 7.4) using REMI homogenizer fitted with a teflon plunger. The homogenate was centrifuged at $10,000 \mathrm{rpm}$ at $4^{\circ} \mathrm{C}$ for $15 \mathrm{~min}$ and the supernatant was used for the determination of antioxidant liver enzymes like superoxide dismutase (SOD), catalase and glutathione peroxidase (GSH-Px). 
Analytical Methods

Fasting blood glucose was measured by glucose oxidaseperoxidase (GOD-POD) method in $\mathrm{mg} / \mathrm{dl}$ using a digital glucometer (Braun Omnitest ${ }^{R}$ EZ, Germany) [11]. Creatinine estimation was carried out in both serum and urine samples [12]. Blood urea was estimated by enzymatic UVkinetic method [13]. The activity of SOD was assayed in a Daytona analyser using commercially available diagnostic SOD kit [14]. The activity of catalase was assayed based on the hydrogen peroxide decomposition method [15]. The activity of glutathione peroxidase was assayed in an automatic analyser using glutathione peroxidase kit [16].

Histopathological studies

At the end of the study, the rats were sacrificed, whole pancreas from each animal was removed, washed in normal saline and fixed in $10 \%$ formalin, embedded in paraffin and sections of 3-5 $\mu$ thickness were cut and routinely stained with basic dye hematoxylin and acidic dye eosin to differentiate the nucleus and cytoplasm. The sections were studied for the islet cell characteristics using a binocular compound microscope.

\section{Statistical analysis}

All the values were expressed as mean \pm standard error of mean (SEM). Statistical difference was evaluated by using one way analysis of variance (ANOVA) followed by Turkeys post hoc test. Data were considered statistically significant at $P$ value $\leq 0.05$.

\section{Results}

Effect of leaf extract on blood glucose level

The anti-hyperglycemic effect of the extract on the fasting blood glucose levels of diabetic rats is shown in Table 1. Administration of streptozotocin increased the blood glucose level by $68.7 \%$ in diabetic control rats which was maintained over a period of 4 weeks. Daily treatment of ethanol extract of $T$. foenum graecum leaves at a concentration of 250 and $500 \mathrm{mg} / \mathrm{kg}$ b.w. for a period of 28 days led to a dose dependent fall in the blood glucose levels by $23.5 \%(P=0.000)$ and $31.2 \%$ $(P=0.000)$ respectively. The glucose lowering effect of the extract seems to reach a maximum after 25 days of treatment and remained almost constant during the next 4-5 days. The effect was more pronounced with animals receiving $500 \mathrm{mg} / \mathrm{kg}$ b.w. of extract which can be compared to that of glibenclamide. The fasting glucose levels in normal control rats and normal control rats fed with the extracts were found to be stable all throughout the experimental period.

Effect of leaf extract on body weight

Prior to streptozotocin administration, there was no significant difference in the average body weight of all the seven groups of experimental animals. By the end of the first week after DM was experimentally induced, the weights of group $D, E, F$, and $G$ were significantly reduced as shown in Table 2. This weight loss continued for 4 weeks in diabetic control animals $(36.3 \%)$. However, the weight of animals in groups $\mathrm{F}$ and $\mathrm{G}$ increased by $42 \%(P=0.000)$ and $44.9 \%$ $(P=0.000)$ on treatment with 250 and $500 \mathrm{mg} / \mathrm{kg}$ b.w. of $T$. foenum graecum leaf extract. At the end of the experimental period there was a significant difference in the weights of groups $\mathrm{F}$ and $\mathrm{G}$ as compared to group $\mathrm{D}$. Animals in groups $\mathrm{A}, \mathrm{B}$ and $\mathrm{C}$ showed an increase in their body weights during the experimental period.

\section{Effect on kidney parameters}

The effect of T. foenum graecum leaf extract on serum and urinary creatinine and serum urea is shown in Table 3. Diabetic control rats exhibited higher serum creatinine, urinary creatinine and blood urea levels compared to those of normal rats. The creatinine and urea levels were significantly decreased by glibenclamide and the extract by 28 days of treatment. The extract at a concentration of $500 \mathrm{mg} / \mathrm{kg}$ b.w. showed a greater decrease in serum creatinine $(73.62 \%, P=0.000)$, urinary creatinine $(62.7 \%, P=0.000)$ and serum urea $(50.6 \%, P=$ 0.000 ) levels which was even better than glibenclamide treated rats. There were no changes in the creatinine and urea levels in normal extract treated controls (group B and C) as compared to the normal control animals.

\section{Effect on liver antioxidant enzymes}

As shown in Table 4, streptozotocin induced diabetic control rats showed a decrease in SOD (3.23 U/mg protein), catalase (6.37 U/min/mg protein) and GSH-Px (3.45 U/mg protein) as compared to the normal rats. Administration of T. foenum graecum leaf extract for 28 days produced a marked increase in the enzyme activities in both $F$ and $G$ groups. There was a greater increase in the activity of SOD $(14.7 \%, P=0.000)$ in diabetic rats treated with $500 \mathrm{mg} / \mathrm{kg}$ b.w. of extract when compared to glibenclamide treated rats. There was an increase in the enzyme activities in group B and $\mathrm{C}$ animals also. 
Table 1 Effect of ethanol extract of Trigonella foenum graecum leaves on glucose level in normal and streptozotocin induced diabetic rats $(N=6)$

Groups $\quad$ Fasting blood glucose levels (mg/dl)

\begin{tabular}{llllll} 
& Day 0 & Day 7 & Day 14 & Day 21 & Day 28 \\
\hline Group A Normal control (0.9 \% NaCl) & $77.0 \pm 1.82$ & $78.25 \pm 0.95$ & $77.75 \pm 2.21$ & $79.50 \pm 2.64$ & $79.25 \pm 1.70$ \\
Group B Normal rats with extract (250 mg/kg b.w) & $78.75 \pm 2.62$ & $78.0 \pm 3.16$ & $78.50 \pm 2.88$ & $79.25 \pm 2.21$ & $79.50 \pm 1.29$ \\
Group C Normal rats with extract (500 $\mathrm{mg} / \mathrm{kg} \mathrm{b.w)}$ & $78.50 \pm 3.10$ & $79.25 \pm 2.50$ & $78.75 \pm 2.50$ & $79.75 \pm 2.98$ & $78.25 \pm 2.75$ \\
Group D STZ induced diabetic control & $246.25 \pm 9.53^{*}$ & $284.0 \pm 5.47^{*}$ & $309.50 \pm 8.73^{*}$ & $319.75 \pm 7.80^{*}$ & $319.50 \pm 8.66^{*}$ \\
Group E STZ+ glibenclamide (0.5 mg/kg b.w) & $248.50 \pm 13.52$ & $222.2 \pm 7.27^{* *}$ & $190.0 \pm 4.54^{* *}$ & $178.25 \pm 6.80^{* *}$ & $157.75 \pm 8.95^{* *}$ \\
Group F STZ+ extract (250 mg/kg b.w) & $248.25 \pm 10.65$ & $240.0 \pm 12.27^{* *}$ & $226.50 \pm 8.58^{* *}$ & $208.5 \pm 7.41^{* *}$ & $189.75 \pm 6.39^{* *}$ \\
Group G STZ+ extract (500 mg/kg b.w) & $243.25 \pm 12.03$ & $229.0 \pm 11.40^{* *}$ & $204.0 \pm 6.21^{* *}$ & $184.50 \pm 5.44^{* *}$ & $167.25 \pm 7.80^{* *}$ \\
\hline
\end{tabular}

Values are expressed as mean \pm S.E.M.; *- significantly different from normal control $(P \leq 0.05)$; **- significantly different from diabetic control $(P \leq 0.05)$

Histopathological studies

As shown in Fig. 1, in the diabetic group, degeneration with reduction in the number and reduced dimensions of the islets were observed in the pancreas. In animals treated with $250 \mathrm{mg} / \mathrm{kg}$ b.w. of the extract, the restoration of the normal cellular population and size of islets were noted especially in the central $\beta$ cell region. In animals treated with $500 \mathrm{mg} / \mathrm{kg}$ b.w. of the extract, there was not only an increase in the cellular population and size of the islets but also there was an increase in the number of islets noted. The regeneration noted in the $\beta$ cell regions was comparable to that noted with glibenclamide.

\section{Discussion}

Streptozotocin, N-[methylnitrocarbamoyl]-D-glucosamine, is a potent methylating agent for DNA and acts as nitric oxide donor in pancreatic cells. $\beta$ cells are particularly sensitive to damage by nitric oxide and free radicals because of their low levels of free radical scavenging enzymes [17].
For the study of antihyperglycemic agents, streptozotocin induced hyperglycemia in rodents is considered to be a good preliminary screening model [18].

Streptozotocin induced diabetes produced a significant increase in glucose levels. Treatment with ethanol extract of $T$. foenum graecum leaves showed significant decrease in glucose levels which was near to glibenclamide treated control. Decrease in blood glucose levels were found to be more effective with $500 \mathrm{mg} / \mathrm{kg}$ b.w. of extract which showed its dose dependent effects. Glibenclamide showed rapid normalization of blood glucose due to its insulin releasing effects. Earlier studies by various workers have shown the antihyperglycemic activity of $T$. foenum graecum seeds in a dose dependent manner in experimentally induced diabetic rats $[19,20]$. The antidiabetic plant extracts may involve one or more compounds which decrease blood glucose suggesting that the natural constituents could act synergistically to induce a hypoglycemic effect [21].

Induction of diabetes with streptozotocin is associated with a characteristic loss of body weight, which is probably due to muscle wasting [22]. In our study, there was a

Table 2 Effect of treatment of Trigonella foenum graecum leaf extract on body weight of normal and streptozotocin induced diabetic rats $(N=6)$

\begin{tabular}{|c|c|c|c|c|c|}
\hline \multirow[t]{2}{*}{ Groups } & \multicolumn{5}{|c|}{ Average body weight (g) } \\
\hline & Day 1 & Day 7 & Day 14 & Day 21 & Day 28 \\
\hline Group A Normal control rats $(0.9 \% \mathrm{NaCl})$ & $142.50 \pm 5.0$ & $146.25 \pm 2.50$ & $152.50 \pm 5.0$ & $160.0 \pm 4.08$ & $166.25 \pm 4.78$ \\
\hline Group B Normal rats with extract $(250 \mathrm{mg} / \mathrm{kg}$ b.w) & $140.0 \pm 0.0$ & $145.0 \pm 4.08$ & $153.75 \pm 4.78$ & $158.75 \pm 4.78$ & $163.75 \pm 4.71$ \\
\hline Group C Normal rats with extract ( $500 \mathrm{mg} / \mathrm{kg}$ b.w) & $140.0 \pm 8.16$ & $146.25 \pm 4.78$ & $153.75 \pm 7.50$ & $161.25 \pm 8.53$ & $165.0 \pm 9.12$ \\
\hline Group D STZ induced diabetic control & $135.50 \pm 5.77$ & $115.0 \pm 5.77^{*}$ & $105.0 \pm 5.77 *$ & $95.0 \pm 4.08^{*}$ & $86.25 \pm 4.78^{*}$ \\
\hline Group E STZ+ glibenclamide $(0.5 \mathrm{mg} / \mathrm{kg}$ b.w $)$ & $132.5 \pm 05.0$ & $120.0 \pm 8.16^{* *}$ & $125.0 \pm 5.77 * *$ & $123.75 \pm 4.78^{* *}$ & $126.25 \pm 2.50 * *$ \\
\hline Group F STZ+ extract (250 mg/kg b.w) & $127.5 \pm 05.0$ & $117.50 \pm 2.88^{* *}$ & $116.25 \pm 4.78^{* *}$ & $120.0 \pm 4.08^{* *}$ & $122.5 \pm 2.88^{* *}$ \\
\hline Group G STZ+ extract (500 mg/kg b.w) & $133.75 \pm 4.78$ & $121.25 \pm 2.50^{* *}$ & $123.75 \pm 2.50^{* *}$ & $124.50 \pm 4.20 * *$ & $125.0 \pm 4.08^{* *}$ \\
\hline
\end{tabular}

Values are expressed as mean \pm S.E.M.; *- significantly different from normal control $(P \leq 0.05)$; **- significantly different from diabetic control $(P \leq 0.05)$ 
Table 3 Effect of treatment of Trigonella foenum graecum leaf extract on serum creatinine, urinary creatinine and serum urea levels in normal and streptozotocin induced diabetic rats $(N=6)$

\begin{tabular}{lllll}
\hline Groups & Treatment & Serum creatinine $(\mathrm{mg} / \mathrm{dl})$ & Urinary creatinine $(\mathrm{mg} / \mathrm{day})$ & Serum urea $(\mathrm{mg} / \mathrm{dl})$ \\
\hline A & Normal control rats $(0.9 \% \mathrm{NaCl})$ & $0.47 \pm 0.04$ & $18.72 \pm 1.83$ & $23.74 \pm 0.73$ \\
B & Normal rats with extract $(250 \mathrm{mg} / \mathrm{kg} \mathrm{b.w)}$ & $0.41 \pm 0.08$ & $18.72 \pm 0.62$ & $23.62 \pm 0.79$ \\
C & Normal rats with extract $(500 \mathrm{mg} / \mathrm{kg} \mathrm{b.w})$ & $0.36 \pm 0.05^{*}$ & $18.32 \pm 0.36$ & $23.42 \pm 0.74$ \\
D & STZ induced diabetic control & $1.82 \pm 0.17^{*}$ & $51.52 \pm 3.76^{*}$ & $61.94 \pm 1.54^{*}$ \\
E & STZ+ glibenclamide $(0.5 \mathrm{mg} / \mathrm{kg} \mathrm{b.w)}$ & $0.60 \pm 0.07^{* *}$ & $23.61 \pm 2.38^{* *}$ & $29.73 \pm 0.59 * *$ \\
F & STZ+ extract $(250 \mathrm{mg} / \mathrm{kg} \mathrm{b.w)}$ & $0.50 \pm 0.03^{* *}$ & $22.22 \pm 2.30^{* *}$ & $32.63 \pm 0.29^{* *}$ \\
G & STZ+ extract $(500 \mathrm{mg} / \mathrm{kg}$ b.w $)$ & $0.48 \pm 0.01^{* *}$ & $19.17 \pm 0.84^{* *}$ & $30.55 \pm 0.44^{* *}$ \\
\hline
\end{tabular}

Values are expressed as mean \pm S.E.M.; *- significantly different from normal control $(P \leq 0.05)$; **- significantly different from diabetic control $(P \leq 0.05)$

significant weight loss in the diabetic rats, whereas treatment with the ethanol extract of leaves of $T$. foenum graecum at both the doses showed improvement in their body weight, indicating that the extract had beneficial effect in preventing loss of body weight of diabetic rats. The probable mechanism is due to its effect in controlling muscle wasting [23]. The metabolic disorders were corrected after the administration of plant extract for 28 days as shown by reduction in polyphagia, polyuria and polydipsia in diabetic rats treated with plant extract. This could be the result of improved glycemic control produced by ethanol extract of $T$. foenum graecum.

Diabetic nephropathy is the leading cause of DM related morbidity and mortality. The pathogenesis of diabetic nephropathy is related to chronic hyperglycemia and hemodynamic alterations in renal microcirculation and structural changes in glomerulus as evident by the significant elevation in creatinine and urea levels [24]. Elevated creatinine and urea levels were significantly decreased in diabetic rats treated with $T$. foenum graecum extract which indicated its beneficial effects on kidney. The result indicate that the ethanol extract of $T$. foenum graecum leaves does not alter the kidney function, as it is evident from the normal creatinine and urea levels in normal control animals treated with the extract (both 250 and $500 \mathrm{mg} / \mathrm{kg}$ b.w.) for a period of 28 days.

Diabetes is usually accompanied by increased production of free radicals [25]. Free radicals are capable of damaging cellular molecules, DNA, proteins and lipids leading to altered cellular functions [26]. Abnormally high levels of free radicals and simultaneous decline of antioxidant defence mechanisms can lead to increased lipid peroxidation and development of insulin resistance [27]. In the present study, diabetic control rats showed significant decrease in SOD, catalase and GSH-Px levels in rat liver homogenate compared to normal rats, indicating dysfunction in antioxidant defensive system. Treatment with ethanol extract of $T$. foenum graecum leaves increased SOD, catalase and GSHPx levels in diabetic rat liver homogenates which were comparable to that of glibenclamide treated rats. Vitamin $\mathrm{C}$ and $\beta$ carotene have been shown to be present in $T$. foenum graecum leaves [28]. Effect of Vitamin C, E and $\beta$ carotene in elevating the antioxidant enzyme activities in diabetic rats has been proved [29]. Phenolics, which are the potential antioxidants are also present in $T$. foenum graecum leaves [30]. So, the activity of the extract in the present study is probably due to the presence of Vitamin $C, \beta$

Table 4 Effect of ethanol extract of Trigonella foenum graecum leaves on liver antioxidant enzymes in normal and streptozotocin induced diabetic rats $(N=6)$

\begin{tabular}{lllll}
\hline Groups & Treatment & $\begin{array}{l}\text { Superoxide dismutase } \\
\text { (units/mg protein) }\end{array}$ & $\begin{array}{l}\text { Catalase } \\
\text { (units/min/mg protein) }\end{array}$ & $\begin{array}{l}\text { Glutathione peroxidase } \\
\text { (units/mg protein) }\end{array}$ \\
\hline A & Normal control rats $(0.9 \% \mathrm{NaCl}$ ) & $10.50 \pm 0.54$ & $10.70 \pm 1.13$ & $5.73 \pm 0.28$ \\
B & Normal rats with extract $(250 \mathrm{mg} / \mathrm{kg} \mathrm{b.w)}$ & $12.39 \pm 0.75^{*}$ & $11.12 \pm 0.40$ & $6.08 \pm 0.18$ \\
C & Normal rats with extract $(500 \mathrm{mg} / \mathrm{kg} \mathrm{b.w)}$ & $14.15 \pm 0.26^{*}$ & $11.35 \pm 0.42$ & $6.30 \pm 0.24^{*}$ \\
D & STZ induced diabetic control & $3.23 \pm 0.30^{*}$ & $6.37 \pm 0.48^{*}$ & $3.45 \pm 0.36^{*}$ \\
E & STZ+ glibenclamide $(0.5 \mathrm{mg} / \mathrm{kg} \mathrm{b.w)}$ & $10.02 \pm 0.33^{* *}$ & $8.82 \pm 0.63^{* *}$ & $5.26 \pm 0.27^{* *}$ \\
F & STZ+ extract $(250 \mathrm{mg} / \mathrm{kg} \mathrm{b.w)}$ & $10.08 \pm 0.43^{* *}$ & $7.52 \pm 0.61^{* *}$ & $4.93 \pm 0.16^{* *}$ \\
G & STZ+ extract $(500 \mathrm{mg} / \mathrm{kg} \mathrm{b.w)}$ & $11.50 \pm 1.26^{* *}$ & $8.32 \pm 0.40^{* *}$ & $5.48 \pm 0.17^{* *}$ \\
\hline
\end{tabular}

Values are expressed as mean \pm S.E.M.; *- significantly different from normal control $(P \leq 0.05)$; **- significantly different from diabetic control $(P \leq 0.05)$ 
Fig. 1 Photomicrographs of rat pancreas stained by $\mathrm{H}$ and $\mathrm{E}$ stain of normal $\mathbf{a}$ and diabetic $\mathbf{b}$ rats and effects of glibenclamide c, $250 \mathrm{mg} / \mathrm{kg}$ b.w. ethanol extract d and $500 \mathrm{mg} / \mathrm{kg}$ b.w. ethanol extract $\mathbf{e}$ of Trigonella foenum graecum. Microscope magnification $(40 \mathrm{x})$
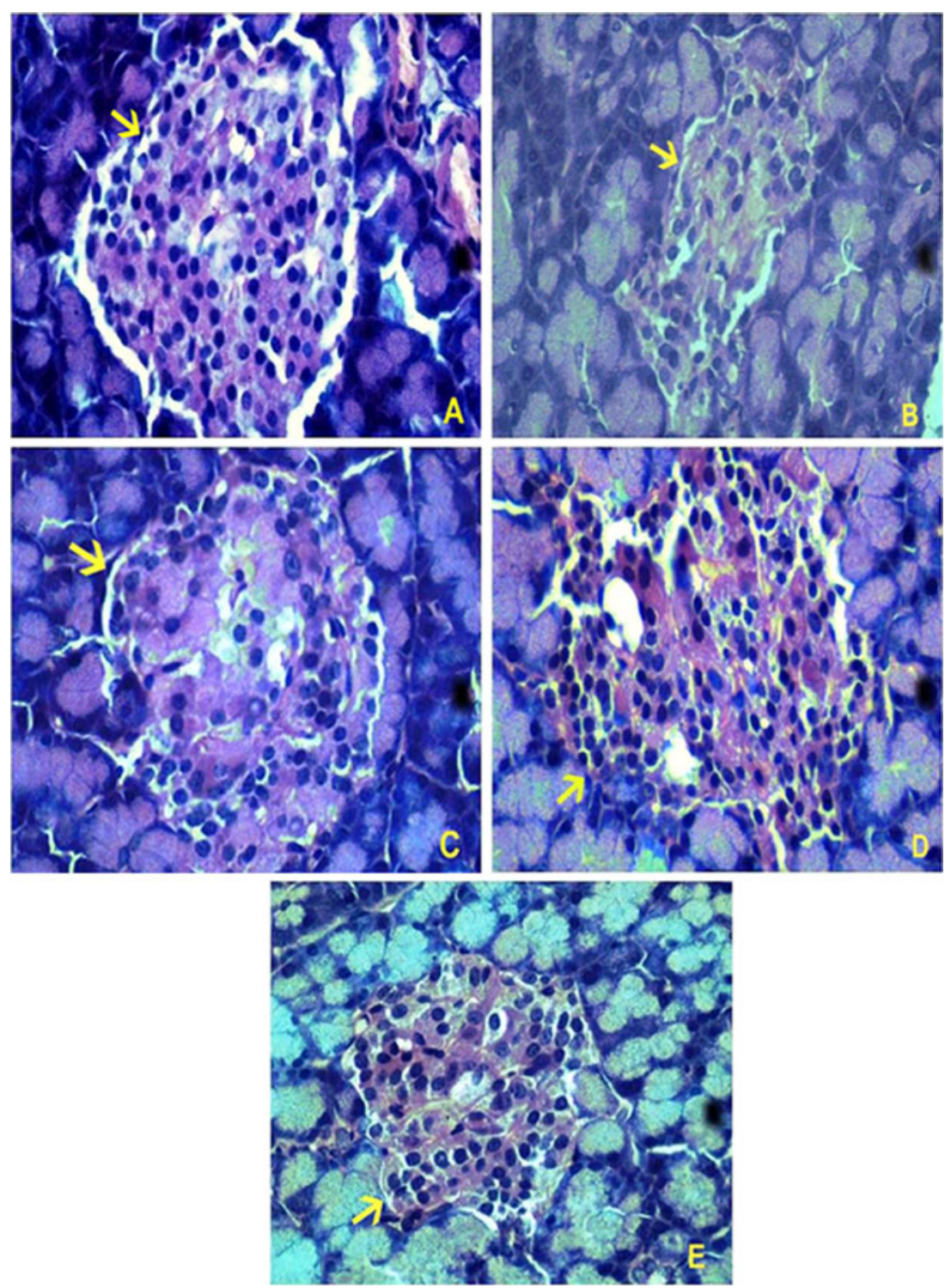

carotene or phenolic antioxidant constituents. An increase in the liver antioxidant enzymes in non diabetic control rats treated with the leaf extract of $T$. foenum graecum showed their non-toxic nature on the liver. The improvement in the enzyme activities in non-diabetic control rats with extracts when compared with the non diabetic control rats without extracts is indicative of better liver function. The result of our study is in agreement with the earlier study on fenugreek seeds [31].

Degeneration and necrosis of the islets of pancreas in diabetic rats was observed similar to the observation of Selvan [32]. Our study has shown the regeneration of islet cells especially in the $\beta$ cell region. Similar effects in streptozotocin treated diabetic animals were reported [33, 34]. The effect of the plant extract in regeneration in the $\beta$ cell region might be due to the presence of $\beta$ carotene [35]. Photomicrographical data in our studies reinforce the healing of pancreas, by $T$. foenum graecum leaf extract as a plausible mechanism of their antidiabetic activity.

In conclusion, our data suggest that the ethanol leaf extract of $T$. foenum graecum possess significant antidiabetic activity as it lowers blood glucose levels in diabetic rats. It also increases body weight of diabetic rats. The ethanol extract was seen to be effective in preventing the rise of creatinine and urea levels and thus improve the kidney functions which were impaired in the streptozotocin induced diabetic rats. In addition to this, the extract was not found to exert any toxic side effects in the extract-fed normal rats as seen by the normal creatinine and urea levels. The extract has shown to induce regeneration and restoration of the normal morphology of the islets of pancreas. Along with the antihyperglycemic activity, the extract was found to possess potential antioxidant activity and enhanced antioxidant status of the diabetic rats. The present study 
suggests that the leaves of $T$. foenum graecum can be utilized for the management of diabetes, but further studies on the nature of active principles involved and their mechanism of action need to be studied.

Acknowledgement The authors wish to thank Dr.H. Basavanagowdappa, Principal, JSS Medical College, Mysore, for the support to carry out this study.

Source of support Funding by minor research project of University of Mysore

\section{Conflicting interest None}

\section{References}

1. Matteucci E, Gimapietro O. Oxidative stress in families of type I diabetic patients. Diabetes Care. 2000;23:1182-6.

2. Lipinski B. Pathophysiology of oxidative stress in diabetes mellitus. J Diabetes Complic. 2001;15:201-10.

3. Shaw JE, Sicree RA, Zimmet PZ. Global estimates of the prevalence of diabetes for 2010 and 2030. Diabetes Res Clin Pract. 2010;87:4-14.

4. Ramachandran A, Snehalatha C, Viswaanthan V. Burden of type 2 diabetes and its complications-the Indian scenario. Curr Sci. 2002;83:1471-6.

5. Hussain AMHE. Hypoglycemic, hypolipidemic and antioxidant properties of combination of Cucurmin from Cucurma longa Linn. And partially purified product from Abroma augusta Linn. In streptozotocin induced diabetes. Indian J Clin Biochem. 2002; 17:33-43.

6. Grover JK, Yadav S, Vats V. Medicinal plants of India with antidiabetic potential. J Ethnopharmacol. 2002;81:81-100.

7. Modak M, Dixit P, Londhe J, Ghaskadbi S, Devasagayam TPA. Indian herbs and herbal drugs used for the treatment of Diabetes. J Clin Biochem Nutr. 2007;40:163-73.

8. Al-Habori M, Raman A. Pharmacological Properties in Fenugreek. In: Petropoulos GA, editor. The Genus Trigonella. London and New York: Taylor and Francis; 2002. p. 163-82.

9. Okigbo RN, Mbajiuka CS, Njoku CO. Antimicrobial potentials of Xylopia aethopica and Occimum gratissimum L. on some pathogens of man. Int J Mol Med Adv Sci. 2005;1:393-7.

10. Venkateswaran S, Pari L. Effect of Coccinia indica leaves on antioxidant status in streptozotocin induced diabetic rats. J Ethnopharmacol. 2003;84:163-8.

11. Trinder P. Determination of blood glucose using an oxidase peroxidase system with a non carcinogen chromogen. J Clin Pathol. 1969;22:158-61.

12. Folin O, Wu H. A system of blood analysis. J Biol Chem. 1919;38:81110.

13. Talke H, Schubert GE. Enzymatic urea determination in the blood and serum in the warburg optical test. Wien Klin Wochenschr. 1965;43:174-75.

14. Woolliams JA, Wiener G, Anderson PH, Mc Murray CH. Variation in the activities of glutathione peroxidise and superoxide dismutase and in the concentration of copper in the blood in various breed crosses of sheep. Res Vet Sci. 1983;34:253-6.
15. Luck H. Catalase: methods of enzymatic analysis. In: Bergmeyer HU, editor. Methods of enzymatic analysis. New York: Academic; 1971. p. 885-93.

16. Paglia DE, Valentine WN. Studies on the quantitative and qualitative characterization of erythrocyte glutathione peroxidise. J Lab Clin Med. 1967;70:158-69.

17. Spinas GA. The dual role of nitric oxide in islets $\beta$ cells. News Physiol Sci. 1999;14:49-54.

18. Ivorra MD, Paya M, Villar A. A review of natural products and plants as potential antidiabetic drugs. J Ethnopharmacol. 1989;27:243-75.

19. Vats V, Grover JK, Rathi SS. Evaluation of antihyperglycemic and hypoglycemic effect of Trigonella foenum graecum Linn, Ocimum sanctum Linn and Pterocarpus marsupium Linn. In normal and alloxanized diabetic rats. J Ethnopharmacol. 2002;79:95-100.

20. Xue WL, Li XS, Zhang J, Liu YH, Wang ZL, Zhang RJ. Effect of Trigonella foenum graecum (fenugreek) extract on blood glucose, blood lipid and hemorrheological properties in streptozotocin induced diabetic rats. Asia Pac J Clin Nutr. 2007;16:422-6.

21. Roy S, Sehgal Padhy BM, Kumar VL. Antioxidant and protective effect of Calatropis procera against alloxan induced diabetes in rats. J Ethnopharmacol. 2005;102:470-3.

22. Swanston-Flatt SK, Day C, Bailey CJ, Flatt PR. Traditional plant treatment for diabetes: Studies in normal and streptozotocin diabetic mice. Diabetologia. 1990;33:462-4.

23. Whitton PD, Hems DA. Glycogen synthesis in perfused liver of streptozotocin diabetic rats. Biochem J. 1975;21:150-3.

24. Cryer PE. Hypoglycemic agents. In: Braunwald E, Fanci AS, Kasper DL, Hanser SL, Longo DL, Jameson JL, (eds). Harrison's Principles of Internal Medicine, 15th ed., vol 2. Mc Graw-Hill; 2001: 2138-2143.

25. Maritim AC, Sanders RA, Watkins JB. Diabetes, oxidative stress and antioxidants: A review. J Biochem Mol Toxicol. 2003;17:24-38.

26. Oberlay LW. Free radicals and diabetes. Free Radic Biol Med. 1988;5:113-24.

27. Garg MC, Bansal DD. Protective antioxidant effect of vitamin C and $\mathrm{E}$ in streptozotocin induced diabetic rats. Indian J Exp Biol. 2000;38:101-4.

28. Srinivasan K. Fenugreek (Trigonella foenum graecum): A review of health beneficial physiological effects. Food Rev Int. 2006;22:203-24.

29. Mekinova D, Chorvathova V, Volkovova K, Staruchova M, Grancicova E, Klvanova J, Ondreicka R. Effect of intake of exogenous vitamin C, E and $\beta$ carotene on the antioxidative status in kidneys of rats with streptozotocin induced diabetes. Nahr. 1995;39:257-61.

30. Ramya P, Sudisha J, Lakshmidevi N, Aradhya SM. Antibacterial and anti-oxidant activities of fenugreek (Trigonella foenum graecum L.) Leaves. Res J Med Plant. 2011;5:695-705.

31. Muralidhara, Narasimhamurthy K, Viswanatha S, Ramesh BS. Acute and subchronic toxicity assessment of debitterized fenugreek powder in the mouse and rat. Food Chem Toxicol. 1999;37:831-8.

32. Selvan VT, Manikandan L, Senthil Kumar GP, Suresh R, Kakoti BB, Gomathi P, Kumar DA, Saha P, Mazumder UK. Antidaibetic and antioxidant effect of methanol extract of Artanema sesamoides in streptozotocin induced diabetic rats. Int J Appl Res Nat Prod. 2008;1:25-33.

33. Shanmugasundaram ER, Gopinath KL, Radha KS, Rajendran VM. Possible regeneration of the islets of langerhans in streptozotocin diabetic rats given Gymnema sysvestre leaf extracts. J Ethnopharmacol. 1990;30:265-79.

34. Xiu LM, Miura AB, Yamamoto K, Kobayashi T, Song QH, Kitamura $\mathrm{H}$, Cyong JC. Pancreatic islet regeneration by ephedrine in mice with streptozotocin induced diabetes. Am J Chin Med. 2001;29:493-500.

35. Nagappa AN, Thakurdesai PA, Venkat Rao N, Jiwan Singh M. Antidiabetic activity of Terminalia catappa Linn. Fruits. J Ethnopharmacol. 2003;88:45-50. 